Vol. 2, n. 3 - Edição Especial: Ciclos Formativos em Ensino de Ciências.

\title{
Trabalhando a dinâmica de rotação na educação básica a partir do funcionamento de Hand Spinners
}

\section{Working with basic rotation in education from the operation of Hand Spinners}

Taís Regina Hansen (tais.rhansen@gmail.com)

Universidade Federal da Fronteira Sul - UFFS

\begin{abstract}
Resumo: Mesmo sendo tão frequentes as mudanças de nossa sociedade, as formas de ensino aprendizagem permanecem sem alterações á décadas. Ainda há muitos professores que adotam o modelo educacional fundamentado na transmissão de conhecimentos, tornando assim, a Física um ensino vazio de significados e uma tarefa pouco prazerosa, ou até mesmo frustrante. Portanto, a maneira como a disciplina é instruída nas escolas deve ser repensada. Nesse sentido as atividades de investigação e demonstrações simples se caracterizam como ótimos recursos didáticos, tendo em vista que as mesmas promovem uma maior compreensão dos conteúdos, além de desenvolver a capacidade crítica e proporcionar o estímulo. Na Base Nacional Comum Curricular (BNCC), pressupõe-se uma aprendizagem com conteúdos voltados para o cotidiano do estudante, fato que vem sendo desconsiderado em virtude dos vestibulares, que exigem a memorização e reprodução dos conceitos. Assim, realizou-se uma prática com o $1^{\circ}$ ano do Ensino Médio no centro educacional La Salle Medianeira onde buscamos, entre outros aspectos, a ligação de conceitos físicos referentes a dinâmica das rotações com o cotidiano dos estudantes, a fim de tornar o processo de ensino-aprendizagem prazeroso e, desta forma, significativo.
\end{abstract}

Palavras-chave: Práticas educativas; Dinâmica de rotações; Ensino-aprendizagem.

Abstract: Even as frequent as the changes in our society, the forms of teaching remain unchanged. There are still many teachers who have adopted or the educational model based on the transmission of knowledge, thus becoming a physics course with empty meanings and an unpleasant, or even frustrating task. Therefore, the way discipline is taught in schools must be compensated. In this sense, research activities and simple tools can be characterized as the best didactic resources, since they promote a better understanding of the contents, as well as develop a critical capacity and stimulate their use. At the Common National Curriculum Base (BNCC), press learning with contents aimed at the everyday student, a fact that has been disregarded due to the entrance exams, which reproduces the memorization and reproduction of concepts. Thus, he performed a practice with the 1st year of high school in the educational center La Salle Medianeira where we seek, among other aspects, a link of phisical concepts to rotational skills with 


\section{Vol. 2, n. 3 - Edição Especial: Ciclos Formativos em Ensino de Ciências.}

everyday students, an end of process or teaching-learning process pleasurable and thus meaningful.

keywords: Educational practices; Rotation dynamics; Teaching-learning.

\section{INTRODUÇÃO}

$\mathrm{Na}$ contemporaneidade as adoções ao modelo de ensino tradicional, fundamentado na transmissão e recepção de conhecimento, se fazem evidente e amplamente utilizados em nosso contexto escolar. Esse fato é ainda mais comum no ensino da Física, onde a complexidade dos conteúdos faz com que a maioria dos educadores adote os métodos propedêuticos de ensino, tornando o ensino desta disciplina, uma tarefa pouco prazerosa e frustrante em nossa educação básica. Além disso, na maioria das vezes o ensino de Física está baseado na memorização e reprodução de fórmulas e listas de problemas, a fim de capacitar o estudante para os vestibulares, assim, o estudante não compreende a inter-relação dos conceitos estudados em sala de aula com o que acontece em seu cotidiano, tornando a Física um ensino vazio de significados.

De acordo com os Parâmetros Curriculares Nacionais para o Ensino Médio (PCNEM) (BRASIL, 1999) e nas suas orientações complementares (PCN+) (BRASIL, 2002), documentos em vigor na data do planejamento e aplicação da sequência didática, percebemos que a forma como a disciplina de Física é apresentada está distorcida e muito distante do seu real propósito. Uma vez que, o documento prevê que a Física apresentese como um "conjunto de competências específicas que permitam perceber e lidar com os fenômenos naturais e tecnológicos, presentes tanto no cotidiano mais imediato quanto na compreensão do universo distante" (PCN+, 2002, p.56).

Portanto, assim como nas outras ciências, na Física o estudante não deve memorizar os enunciados, leis e fórmulas, é necessário que ele entenda os conceitos, associe com o mundo em que vive, compreendendo e entendendo os fenômenos observados unidos a suas explicações. Somente assim o interesse em aprender física dos estudantes poderá ser estimulados, para tanto, a maneira como a disciplina é instruída nas escolas deve ser repensada. 


\section{Vol. 2, n. 3 - Edição Especial: Ciclos Formativos em Ensino de Ciências.}

Galiazzi e Gonçalves (2004) afirmam que a maneira como um professor desenvolve um determinado assunto em sala de aula influencia o aluno a gostar ou não do que está sendo tratado. Sendo assim, para que os estudantes tenham maior interesse nesta ciência, e, por conseguinte melhore sua aprendizagem, métodos diferenciados dos modelos tradicionais de ensino se tornam fundamentais. Nesse sentido, buscando promover uma prática por meio de um modelo explicativo enriquecido de técnicas e metodologias diferenciadas, desenvolvendo uma aula voltada aos conteúdos da cinemática de rotação, utilizamos de Hand Spinner ${ }^{1}$ como uma ferramenta didática. Dessa forma, apresentamos a seguir a contextualização da atividade.

\section{DESCRIÇÃO DAS ATIVIDADES}

A prática aqui relatada se configura como fruto de uma experiência vivenciada durante a disciplina de Instrumentação para o Ensino de Física e Ciências III, do curso de Física - Licenciatura da Universidade Federal da Fronteira Sul. A mesma foi desenvolvida com estudantes do $1^{\circ}$ ano do ensino médio em um centro educacional, da rede privada de ensino, localizada no noroeste do estado do Rio Grande do Sul. Esta instituição de ensino atende a estudantes desde a Educação Infantil até o Ensino Médio, auxiliando crianças e adolescentes em seu desenvolvimento integral.

A ministração da aula teve a duração de dois períodos, ou seja, 1 hora e 40 minutos. A mesma envolveu em sua preparação diversos estudos e planejamentos. Para melhor execução optou-se por utilizar como recursos o quadro negro, o dispositivo de projeção multimídia (data show) e spinners, trazidos pelos próprios estudantes. Metodologicamente fomos guiados pelos Três Momentos Pedagógicos (DELIZOICOV; ANGOTTI; PERNAMBUCO, 2002). A problematização inicial esteve pautada em questionamentos aos estudantes, as quais tiveram como base uma pequena competição com os spinners. Esse momento permite ao estudante uma noção sobre o que será trabalhado, além de possibilitar que o mesmo se sinta instigado a adquirir novos

\footnotetext{
${ }^{1}$ Hand Spinner - Equipamento que ao ser impulsionado realiza movimento de rotação. É utilizado como amenizador de ansiedade e estresse.
} 


\title{
Vol. 2, n. 3 - Edição Especial: Ciclos Formativos em Ensino de Ciências.
}

conhecimentos sobre o assunto, caracterizando, portanto, uma etapa essencial na execução da aula.

\begin{abstract}
Mais do que simples motivação para se introduzir um conteúdo específico, a problematização inicial visa à ligação desse conteúdo com situações reais que os alunos conhecem e presenciam, mas que não conseguem interpretar completa ou corretamente porque, provavelmente não dispõem de conhecimentos científicos suficientes (DELIZOICOV; ANGOTTI, 1991, p. 29).
\end{abstract}

Em seguida, guiados pela análise da problematização buscamos estruturar as ideias, aplicar e promover o conhecimento com um caráter interdisciplinar e instigante. Assim, na organização do conhecimento utilizamos de ferramentas e atividades variadas que se adequavam com a estrutura base da temática, selecionando os conteúdos conforme a necessidade e levando os educandos a "perceber a existência de outras visões e explicações para as situações e fenômenos problematizados e, de outro, a comparar esse conhecimento com o seu, de modo a usá-lo, para melhor interpretar aqueles fenômenos e situações" (DELIZOICOV; ANGOTTI, 1991, p. 55).

E, por fim, “é, particularmente importante considerar esta função da 'aplicação do conhecimento' é ela que, ampliando o conteúdo programático, extrapola-o para uma esfera que transcende o cotidiano do aluno" (DELIZOICOV; ANGOTTI, 1982, p. 150). Permitindo que o conhecimento dialogado, seja utilizado, aplicado e trocado com sua família, amigos, colegas e comunidade de forma que a aprendizagem esteja na vida e cotidiano do e na formação do estudante. Tendo em vista os Três Momentos Pedagógicos (MP) caracterizados anteriormente, em seguida apresentamos os resultados das atividades realizadas.

\section{DISCUSSÃO DA PRÁTICA}

A prática realizada iniciou-se com a sugestão de uma competição entre os estudantes que haviam trazido para a aula seus spinners. Assim, orientamos que os estudantes posicionassem seus brinquedos e ao comando os fizessem girar, desta maneira, observamos qual objeto giraria por mais tempo e a partir disso iniciamos nossa problematização inicial. Questionamos os estudantes sobre o porquê de alguns spinners 


\section{Vol. 2, n. 3 - Edição Especial: Ciclos Formativos em Ensino de Ciências.}

girarem por mais tempo em comparação a outros modelos, bem como por qual motivo alguns efetuavam o giro mais rapidamente.

Constatamos que os estudantes não possuíam significativos conhecimentos sobre o assunto referente à cinemática de rotações, ou não os associavam ao movimento dos Hand Spinners, tendo em vista que as respostas não foram às esperadas, fato que já é previsto por Delizoicov e Angotti (1992, p. 29) ao afirmarem que:

\footnotetext{
a problematização poderá ocorrer pelo menos em dois sentidos. Por um lado, o aluno já poderá ter noções sobre as questões colocadas, fruto da aprendizagem anterior na escola ou fora dela. (...) Por outro lado, a problematização pode permitir que o aluno sinta a necessidade da aquisição de outros conhecimentos que ainda não detém.
}

Visto que a partir do primeiro momento concluímos a necessidade dos conceitos serem abordados de forma detalhada, em nosso segundo momento pedagógico, a organização do conhecimento, optamos por dividir o assunto em três tópicos: tempo de giro, velocidade de giro e equilíbrio dos spinners, respectivamente. Vale ressaltar que todos os conceitos abordados durante a aula, a fim de explicar o funcionamento dos spinners, já haviam sido trabalhados anteriormente. Desta maneira, iniciamos nossa explicação falando sobre atrito, tópico este, previsto nos $\mathrm{PCN}+$ e também na Base Nacional Comum Curricular (BNCC) atualmente em vigor, uma vez que, interfere de forma resistiva á todos os movimentos presentes em nosso dia a dia. Para tanto, explicamos o conceito e após desmontamos um spinner e mostramos os seus rolamentos, apresentando a região com atrito cinético que interferia e provocava oposição ao movimento, além de salientar que quanto mais baixo for este atrito por mais tempo o Hand Spinner irá manter sua rotação.

Logo após, buscando discutir o conceito de massa, realizamos uma comparação entre duas situações semelhantes: Na primeira pedimos para os estudantes imaginar um veículo de passeio, se deslocando com uma velocidade constante, enquanto na segunda um carro de brinquedo se deslocando com a mesma velocidade. Então perguntamos e se nos posicionássemos na frente de ambos, aplicando uma força oposta ao movimento buscando para-los, em qual das situações seria mais fácil? Todos os estudantes responderam rapidamente que seria mais fácil parar o carro de brinquedo. Em vista desta 


\section{Vol. 2, n. 3 - Edição Especial: Ciclos Formativos em Ensino de Ciências.}

resposta, destacamos a influência que a massa exerce sobre os diferentes movimentos, uma vez que é uma propriedade que dificulta a variação do movimento de um objeto.

Posteriormente, explicitamos que além da quantidade de massa alterar os movimentos, a forma como esta está distribuída no spinner, ou em qualquer outro objeto, também altera seu movimento, devido ao momento de inércia, que oferece resistência à mudança de velocidade de um corpo, nesse caso velocidade angular. Assim, apresentamos a equação do momento de inércia para os estudantes e a discutimos. Após isso comparamos o spinner que girou por mais tempo com aquele que girou menos tempo, tal qual, os estudantes puderam concluir que quanto mais longe do eixo de rotação a massa está concentrada, maior o momento de inércia. E, como consequência, um corpo em rotação quando estiver acelerado mais difícil é pará-lo. Também, vale lembrar, que nosso PCN+ prevê que estes assuntos sejam trabalhados, a fim de que os estudantes possam "Identificar diferentes movimentos que se realizam no cotidiano e as grandezas relevantes para sua observação (distâncias, percursos, velocidade, massa, tempo, etc.), buscando características comuns e formas de sistematizá-los” (PCN+, p.21).

Por fim, trabalhando o terceiro conceito, iniciamos a explicação do conceito de velocidade angular, onde relacionamos o conceito de massa com o mesmo. Para melhor compreensão deste fenômeno efetuamos um pequeno experimento, para isso, convidamos um estudante a sentar-se em uma cadeira giratória com os braços junto ao peito e o girarmos, ainda girando pedimos para que abrisse os braços e os fechasse novamente até a cadeira parar. Com isso, os estudantes puderam visualizar que no momento que o colega abria os braços a velocidade diminuía, enquanto ao fechá-los a mesma aumentava, fato esse devido a distribuição da massa ficar mais distante do eixo de rotação. Tendo em vista tal fenômeno, novamente comparamos o spinner mais lento com o mais rápido, percebendo que o mais rápido era aquele que possuía a massa mais próxima ao eixo de rotação.

Partindo para o último tópico em questão, iniciamos com uma pergunta: Por que é mais fácil se equilibrar sobre uma bicicleta em movimento do que parada? As respostas fizeram referência ao equilíbrio, porém nenhuma evidenciou alguma ligação do equilíbrio 


\section{Vol. 2, n. 3 - Edição Especial: Ciclos Formativos em Ensino de Ciências.}

com a conservação do momento angular. Segundo o $\mathrm{PCN}+$ os alunos devem "A partir da observação, análise e experimentação de situações concretas como quedas, colisões, jogos, movimento de carros, reconhecer a conservação da quantidade de movimento linear e angular e, por meio delas, as condições impostas aos movimentos” (p.72). Sendo assim, iniciamos nossas explicações sobre o tema que faz ligação entre o momento de inércia e a velocidade angular, conceitos já trabalhados anteriormente.

A partir deste conceito, sugerimos que os estudantes girassem seus spinners na diagonal e em seguida tentassem movimentar os mesmos para a direita e após para a esquerda. Ao exercerem uma força, na tentativa de agitar o brinquedo os estudantes conseguiam sentir uma suposta força no sentido contrário ao movimento que estavam realizando sobre o mesmo. Desta forma, fomos capazes de mostrar aos estudantes como se comporta o momento angular, ou seja, a tendência que um objeto em rotação possui de manter seu eixo de rotação, para assim explicar o porquê de conseguirmos equilibrar tão facilmente os spinners sobre os dedos.

Finalmente, em nosso terceiro momento pedagógico, a aplicação do conhecimento, fornecemos materiais para que os estudantes montassem seus próprios Hand Spinners. Sugerimos que a turma se dividisse em dois grupos e que cada um montasse um Spinner levando em consideração as explicações referentes ao tempo e velocidade de giro, a fim de que, ao final, realizássemos uma competição verificando qual Spinner giraria por mais tempo. Os estudantes se mostraram muito motivados nessa etapa, porém enfrentaram algumas dificuldades quando a montagem do objeto.

Por fim, acreditamos que houve significativos ganhos cognitivos tanto da turma quanto dos professores ministrantes. A oferta de momentos de aula ministrada para futuros professores de Física é de fundamental importância, uma vez que, permitem que a experiência construída em uma aula ministrada estenda-se para prática docente. Além disso, a partir da ministração percebemos que uma aula bem preparada e diferenciada, fora da metodologia tradicional de ensino, é capaz de despertar o interesse dos estudantes, mesmo frente a conceitos complexos, fazendo que os mesmos interajam, apresentem suas opiniões e suas dúvidas, propiciando uma aprendizagem muito mais significativa. 
Vol. 2, n. 3 - Edição Especial: Ciclos Formativos em Ensino de Ciências.

\section{CONCLUSÃO}

Entendemos que a cinemática de rotação está diretamente ligada à atividades desenvolvidas e aplicadas em nosso cotidiano, desde fenômenos naturais como dia e noite, a própria rotação planetária, as rodas dos veículos. Desta forma, vê-se como de suma importância a problematização desse conteúdo na Educação Básica. Porém, este urge com um conjunto de problemáticas a serem enfrentadas, desde a formação dos professores até questões de base didáticas, como os livros didáticos e outros recursos norteadores de fácil acesso que possam ser utilizados pelo professor como ferramentas de construção da aprendizagem, rompendo o ensino propedêutico e trazendo conjunto de materiais, metodologias e conteúdos referente a temática.

Em nosso processo de construção da metodologia educacional, percebemos que ao trabalhar uma temática por meio dos conhecimentos iniciais dos estudantes, nós permitimos que os mesmos construíssem a sua própria aprendizagem, sendo assim, a metodologia se mostrou muito eficaz para um ensino de qualidade. Salientamos ainda, que a proposta foi planejada de acordo com os PCN's, abordando conceitos que estavam previsto neste documento, todavia a BNCC, hoje em vigor, também traz tais habilidades dentro da Competência Específica 1, assim, a sequência pode ser aplicada nos dias atuais. Além disso, percebemos que por meio da ministração ampliamos a visão/concepção sobre a escola e a sala de aula, tornando a nossa formação docente mais significativa.

\section{REFERÊNCIAS}

BRASIL. Base Nacional Comum Curricular (BNCC). Educação é a Base. Brasília, MEC/CONSED/UNDIME, 2018.

BRASIL, Ministério da Educação. Secretaria de Educação Média e Tecnológica. Parâmetros Curriculares Nacionais do Ensino Médio - PCNEM. Brasília: MEC/SEMTEC, 1999.

BRASIL. Ministério da Educação. Secretaria da Educação Média e Tecnológica. Parâmetros Curriculares Nacionais + $(\mathrm{PCN}+)$ - Ciências da Natureza e suas Tecnologias. Brasília: MEC, 2002.

DELIZOICOV, D; ANGOTTI, J, A; Pernambuco; M, M. Ensino de Ciências: Fundamentos e Métodos; colaboração Antônio Fernando Gouvêa da Silva. 4. Ed. São Paulo: Cortez, 2011, p. 173-298. 
Vol. 2, n. 3 - Edição Especial: Ciclos Formativos em Ensino de Ciências.

DELIZOICOV, D.; ANGOTTI, J. A. Metodologia do Ensino de Ciências. São Paulo: Cortez, 1991.

DELIZOICOV, Demétrio; ANGOTTI, José André. Física. São Paulo: Cortez, 1992.

FREIRE, P. Pedagogia do Oprimido. 48. ed. Rio de Janeiro: Paz e Terra, 2005.

GALIAZZI, M. C.; GONÇALVES, F. P. A natureza das atividades experimentais no ensino de ciências: um programa de pesquisa educativa nos cursos de licenciatura. In: MORAES, R. ; (Orgs). Educação em Ciências. Ijuí: Unijuí, 2001, p. 237-252. 